\title{
Discussion on Life Connotations of Domestic and Overseas Music Education
}

\author{
Boqiang Luan \\ Xi’an Peihua University, Xi’an, China
}

Keywords: Music education; Life connotations; Aesthetics

\begin{abstract}
As the form of artistic aesthetic education, the core of music education aims to cultivate students' aesthetic perception and experience, to observe life state of the mankind and to become the life demands of the real look. This is also the life connotation of music education. By sorting out the historical development of domestic and overseas music education in this paper, the author focuses on discussing life connotations of music education from history, education, music and aesthetics and emphasizes on importance of its life connotations on the individual life development, hoping to reflect on the essence of the current music education and let education become the important form to cultivate and lubricate life.
\end{abstract}

Music education is the aesthetic education form that regards music art as the media, hoping to cultivate students' ability to discover, appreciate, create and evaluate aesthetics. The music education with the core of cultivating aesthetic ability pursues for goodness and truth by virtue of the aesthetic life demands, showing the care for life and exploration for life spirit, hoping to realize the perfect life development.

\section{Life connotations of music education in ancient and modern times of China}

Mr. Zong Baihua once said, "progress in history is often accompanied with the pursuit for the source" Tracing back to the history, the development of music education is always related to life. From the beginning of education, music education has the equal important status with other subjects and develops a special role on shaping and perfecting personality.

(1)The music education in the ancient times was originated from the primitive dance and sacrifice activities in the clan society, showing that the mankind looked for the harmony and equilibrium of life in the initial group social activities and coordinated with emotional and physiological desires of existing primitive natural instinct in the survival process through protocol sacrifice and protocol activities, so as to reach the harmonious state. Rooted in the special life state of the mankind, music education, on the one hand, means that the mankind aims to perfect various demands. On the other hand, the clan gains the exchange and communication in the diversified and differential cultural activities. For example, Mr. Xiu Hailin thought that "primitive dance activities don't deny emotional instinct of the mankind, but make them have the aesthetic significance in social activities, indulge themselves in it and make them become the social and humanized emotions through the participation of the concept and idea. This is the educational mode that is associated with the entire social cultural education, instead of teaching a pure dance skill. This is also the pioneer of music education in later generations." As a result, after three generations in ancient times, music education has the basic feature of ritual and music education. Starting from Zhou Gong creating the social institution, he thought that cultivation of a person should reach the consistency in morality and behaviors through interior and exterior. Therefore, he educated people with "music morality, music language and music dance" and made "peace" through "music". Such "peace" exactly makes people become civil and military under the function of music teaching, reflecting in improving and cultivating life morality and spiritual life of individuals, so as to reach "peace" in life and identify meaning of life through "acquisition of ritual and music and coexistence of goodness".

After entering into the Spring and Autumn Period and the Warring States Period, due to profound reform of social economy and politics, ritual and music education established in the Western Zhou 
Dynasty took place the fundamental changes. Under the circumstance, Confucius reconstructed ritual culture, exceeded religious worship by grasping aesthetic thought of life, focused on valuing human life, and created the Confucian music education culture through ritual and music education. The old saying in the Analects goes, "developed from poems, based on rites and achieved in music"; "no benevolence, no rites; no benevolence, no music." In his opinions, only "music" can satisfy the education of the mankind. The aesthetics of "music" will edify inner emotions and moral consciousness of the mankind to finally become "adults" with the spiritual cultivation of humanity. Such activities make people comprehend the realm of life in the experience process of "music". Such realm of life has already broken through the emotional limit, looking for the significance of life by constructing the perfect personality.

After Qin and Han Dynasties, music education of ancient official school was gradually separated from the education, reflecting in satisfying education of "art in entertainment and sacrifice of the court. The occurrence of artists after the Han Dynasty embodied the humanistic spirit contained in Chinese music education in teaching. During the period of the Spring and Autumn Period, scholars cultivated their mind with musical instruments. Learning an artistic skill was just an aspect. What's more, musical instruments made them learn how to behave. In Han Dynasty, Liu Xiang brought musical instruments into the traditional music education, laying a foundation on flourishing musical instruments in later generations. "Theory of musical instruments" was gradually permeating with the "music education" spirit from the ancient times and integrating people's emotional experience of realistic life into the aesthetic perception in life world, so as to gain "unification of aesthetic and life" with the artistic life.

As a result, "music" in ancient times was diphonia. From the perspective of aesthetics, music education emphasizes that "music" will achieve the ultimate goal in education- "music" in human life is too look for "happiness' of life. Mr. Dai Dingcheng showed that "Chinese ancient music education always provided a peaceful place for people and taught people how to survive and how to improve significance of life and enjoy happiness of life. The purpose of life aims to cultivate immature people into the new life that understands how to create life and also enjoys life. Education has to accomplish such a mission.”

(2) If music education in ancient China emphasized people's pursuit for aesthetic and artistic realm of life with the artistic education, music education in modern China enlightens paralytic spirit of ours by music and let people look for a fighting spirit and life power from music, so as to realize the great rejuvenation of Chinese nation. In Liang Qichao's opinions, "in order to change the quality of citizens, poetic music is one of components in spiritual education.” Ancient China always valued tradition of music education. Only the education of poetic music can educate people, thus he proposed that the primary purpose of education was to firstly transform spirit of common people. Only poetic music can bring "goodness to public mind". During the period, scholars who studied abroad introduced a music class in the new classroom and taught students to sing songs, creating the "School Music" in the history of Chinese music education. After the Revolution of 1911, the democratic educator Cai Yuanpei who acted as the Minister of Education in the Nationalist Government set up a music class in the primary schools and institutions of higher learning. In the New Culture Movement, he published the Theory that Aesthetic Education Displaces Religion to elaborate the connotations of music and fine arts.

During the anti-Japanese war period, national middle and primary schools carried out the anti-Japanese singing activities, which not only encouraged people's enthusiasm for anti-Japanese war, but also made national people experience life power and fighting spirit in music. Graduation and March of the Volunteers by Nie Er and Going Back to the Enemies by Xian Xinhai gave people spiritual incentive and made people unify in the calamity of Chinese nation and dared to face up with difficulties to "go ahead, go ahead and go ahead".

After the foundation of new China, the educational policy and syllabus defined the status of music education and stood out the all around development of students' moral, intellectual and physical, implying that school music education was officially used as the aesthetic education. What's more, it emphasized the relationship of students' sound personality shaping and all around 
development in mind and body. In 1999, aesthetic education was listed in the official course standard by the nation. Music education develops an irreplaceable role in aesthetic education. Moreover, it emphasizes that students pay attention to cultivation of emotional value when students gain knowledge and ability, showing the ultimate care for life, motivate life vitality and display beauty of life.

\section{Life connotations of overseas music education}

The overseas music education thought was firstly originated from the ancient Greek. It is said that when Pythagoras passed by the Blacksmith, he heard of the chord of four degrees, three degrees and eight degrees. He thought that as using a hammer to strike, due to different power, there are different sounds. After studying, he found that different chord length will generate the sound with different length. Generally speaking, he was the first one to find out the corresponding relationship between the sound and digit. For this reason, this laid a foundation on developing music education of the west. Actually, the "harmony of digits" by Pythagoras is the harmony of musical sound, which turns to make people reflect on the cosmology. In his opinions, the universe performs the harmonious musical sound under the order combination of various stars. Socrates placed the emphasis of philosophy from cosmology to political ethics. In addition, aesthetic ideology also emphasizes on the utility on the human society. Socrates showed that for the same thing, when it has the suitable purpose and it is useful to people, it is beautiful, vice versa. Afterwards, Plato and Aristotle reflected on aesthetics again and constructed the aesthetic thought of the west. In addition, Plato also expressed the function of music education on cultivating spirit and morality of children in his Utopia. In his opinions, in order to be a real politician, it is necessary to be a musician, because only suitable music can satisfy spiritual demands. This edifies people's character. Meanwhile, music has the harmonious musical sound just like the universe, so music education makes people become a member of "ideal" world with the true, the good and the beautiful. Aristotle once gave more intelligent reflection on aesthetic thought of Plato. In his opinions, it doesn't mean that artistic beauty has no value of the truth. Instead, artistic beauty "seeks knowledge” through imitation. Such "knowledge seeking" is a pursuit for the truth and value.

After entering into the Middle Ages, the combination of music education and religion became a tool for religion to publicize doctrine. Aesthetic thought in the Middle Ages was complicated. On the one hand, it was attached to the religion of theology and also blindly looked for independence of arts. The choral in the Christian church hopes to gain the direct communication of life and angel by singing, purifying their spirit. During the renaissance, in order to oppose to theological religion and make people get out of the theological shackle for human thought, artists thought that life is not given by the God, but people gradually become mature step by step under the natural power. In addition, beauty also shows the special human power for other creatures in the natural selection process. Therefore, the aesthetic ideology in renaissance manifested main features of the man's subjectivity. Art should be improved to the height of philosophy from the study on skills and apply the autonomous thought of the mankind to reflect on existence of individuals. Rousseau indicated that children's education not only should abide by the nature of life growth, but also should value music education in each age group, because only music can affect children's spirit, implying that music education is a matter of concerning that whether each child can become a "natural man" in the education. It can be observed from the music of Beethoven, Mozart and Haydn that it is the self-expression constructed on their life experience. From aesthetic education by Schiller to classical aesthetics by Hegel, Hegel thought that art is the most beautiful. Sensibility and rationality, individuals and general, subjectivity and objectivity in artistic beauty can be highly unified. Music education corresponding to aesthetic education theory pays attention to spiritual perfection and sentimental nobility. Music education can be used to cultivate the sound and correct life attitude of students and improve their personality.

In the 21st century, western countries treat with music of each nation in a new perspective. Under the background of diversified culture, they break through the constraint of western music center theory and focus on diversified culture and nationality of music, especially for cultivating 
individual life by music education. By taking national standards of the American artistic education, the standard show that artistic education has the important significance on cultivating the perfect people. In addition, students' aesthetic emotions can be improved in the integrated artistic education activities and they can experience the most beautiful chapter in life brought by arts and enjoy life connotations through music education.

By sorting out historical development of Chinese and overseas music education, it can be found that music education is always the cultivation and edification on human life. Enrichment of emotions and spirit and nobility of spirit and morality need to internalize emotions into the life value and moral improvement through music education. In other words, music education, as aesthetic education, not only develops an important role in students' all round development, but also exceeds the practical level in today's society wit modernization, so as to notice life, edify spirit in the higher level and improve realm of individual life in realistic situation, hoping to "endow spirit with freedom and activity creativity through cultivation of music arts and maintain a balance between intellect and emotions as cultivating human temperament.

\section{References}

[1] Li Zehou, Philosophical Aesthetic Selection of Li Zehou[M], Changsha, Human People’s Publishing House, 1985.

[2] Zong Baihua, Pursuit for Beauty[M], Nanjing, Jiangsu Education Press, 2005.

[3] Ling Jiyao, History of the Western Aesthetics[M], Beijing: Beijing College Student Press, 2004.

[4] Guo Shengjian, Artistic Education Theory[M], Shanghai, Shanghai Educational Publishing House, 1999.

[5] Dai Dingcheng, Prospect on the Music Education in 21st Century[M], East China Normal University, 2001.

[6] Guan Jianhua, Philosophy of Post-modern Music Education [M], Xi'an, Shaanxi Normal University Press, 2005.

[7] Xiu Hailin, Chinese Ancient Music Education[M], Shanghai, Shanghai Educational Publishing House, 1995

[8] Yi Cunguo, Style of Lyre[M], Baihua Literature and Art Publishing House, 2004.

[9] Liang Qichao, Yin Bing Chuang Shi Hua, quoted from Yu Yuci, edited by Zhang Yuan, Selection of Music Education in Chinese Modern Schools[M], Shanghai Educational Publishing House, 2000. 